\title{
Simple Digital D1S Lamp System with a Power Structure of Flyback Converter and Full-Bridge Inverter
}

\author{
Gang-Youl Jeong \\ Department of Electronic Information Engineering, Soonchunhyang University \\ Soonchunhyang-ro 22, Shinchang-myun, Asan-si, 31538, Republic of Korea \\ gangyoul@sch.ac.kr
}

\begin{abstract}
This paper presents a simple digital DIS lamp system with a power structure of flyback converter and full-bridge inverter using a low-cost 8-bit one-chip microprocessor to optimize the total system size and minimize implementation cost. The DIS lamp is a high intensity discharge lamp used for the headlight lamp of advanced cars. DIS lamp driver in the proposed system can generate high voltage to ignite the lamp. It can effectively control the power required to drive the lamp after the ignition. The proposed driver is consisted of an igniter, a DC-DC converter, a DC-AC inverter, and a control circuit. The DC-DC converter utilizes the flyback converter topology to minimize its component number. It is utilized to generate high ignition voltage of the DIS lamp. When the operation of the proposed system arrives in a steady state, the driver controls the lamp with AC current using the DC-AC inverter. In this paper, the operation principle of the proposed driver is described in details and the operation principle related to the igniter is explained briefly. Experimental results demonstrated that the proposed system had good performance for the DIS lamp.
\end{abstract}

Keywords: DC-AC converter, flyback converter, full-bridge inverter, igniter, one-chip microprocessor

\section{Introduction}

Compared to conventional lamps such as incandescent lamps or fluorescent lamps, high intensity discharge (HID) lamp has many advantages such as higher brightness, higher efficiency, and longer life. Therefore, HID lamps have been widely used for various indoor and outdoor lighting applications such as spotlights inside shopping stores, headlights of cars, LCD projectors, and small power HID lamps [1]. Among these HID lamps, metal halide discharge lamp has many advantages. For example, its consumption power is $40 \%$ less, but its light quantity and durability is three times and four times more, respectively, compared to conventional halogen lamps. In addition, its size of light emission is small. These are essential for advanced cars to have high performance, high efficiency, high stability, and low fuel expenses. Therefore, since 1991, advanced car companies have applied HID lamps for car headlight lamps. They are expanding the lamp using ratio. Korean car companies have also applied them to more cars. HID headlight lamps of advanced cars include D1S lamp. However, D1S lamp needs high voltage pulses more than several kilovolts for starting the discharge between electrodes in the lamps. After the discharge, the lamp must be operated with $\mathrm{AC}$ current to expand their durability and protect them from being black. In addition, because HID lamp shows negative resistance characteristics in the operating region with characteristic of changing its 
resistance over time, the lamp driver must ensure stable operation of the lamp [2]. Therefore, a HID lamp driver needs to include a DC-AC converter to convert low DC voltage to high AC voltage and an igniter to output high DC voltage.

Because a flyback converter has the minimum component number that can easily output high DC voltage using an igniter, the HID lamp driver can utilize flyback converter for the DC-DC converter [3]. Although the operating condition for HID lamp such as D1S lamp varies largely in steady state, the lamp driver must supply an exact current to the lamp. In order to start the lamp, the DC-DC converter must be able to raise the input voltage of the igniter to the operating voltage of the arcgap. When the arc-gap turns on, the induced high DC voltage of the primary side of igniter transformer causes isolation breakdown at the lamp. Therefore, the DC-DC converter must supply enough current to make the lamp's glow-discharge state to become the arc-discharge state. Thus, separate outer current path is needed to overcome the slow response speed of the DC-DC converter. In addition, since the lamp driver controls the lamp power for stable operation after transient state, it must control the lamp current with $\mathrm{AC}$ so that each electrode can consume the current equally. This function can be achieved by using a full-bridge inverter that can operate at low frequency to protect acoustic resonance [4].

In this paper, a simple digital D1S-lamp system with the power structure of a flyback converter and a full-bridge inverter is presented. The controller of the proposed system uses a low-cost 8-bit one-chip microprocessor to optimize the total system size and minimize implementation cost. The lamp driver in the proposed system is consisted of an igniter part, a DC-DC converter, a DC-AC inverter, and a control circuit using microprocessor. Because the flyback converter topology minimizes component number, the DC-DC converter can utilizes the topology. In addition, the flyback converter is used to raise the igniter input voltage to the arcgap operating voltage. When the operation of the proposed system arrives in a steady-state, the proposed driver controls the lamp with AC current using the DC$\mathrm{AC}$ inverter. In this paper, the operation principle of the proposed driver is described in details and the operation principle of the part related to the igniter is explained briefly. Experiments were performed in this study to determine the performance of the proposed driver for the D1S lamp.

\section{System Outline of the HID Lamp Driver}

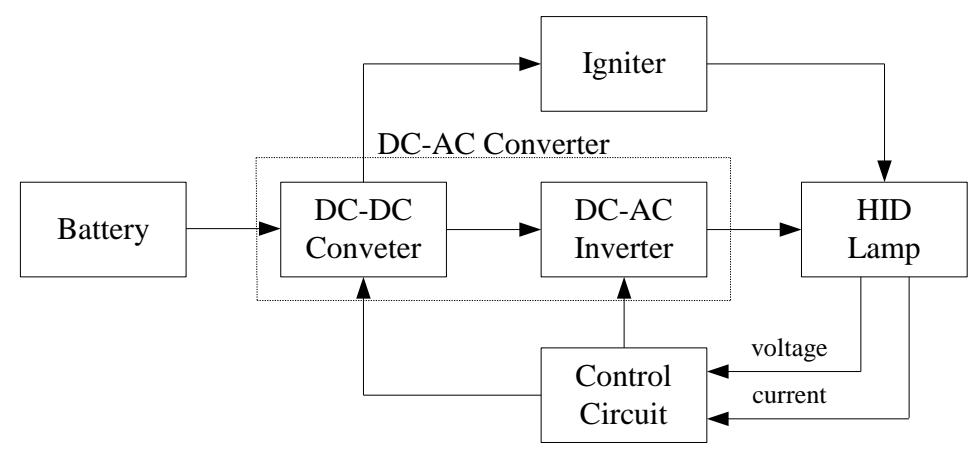

Figure 1. Total System Block Diagram of the HID Lamp System

The HID lamp such as the D1S lamp used as a headlight lamp of car has the following characteristics: 1) its starting voltage for discharge of inner gas is very high; 2) its starting power is very big. Therefore, the driver for the HID lamp included a DC-AC converter to convert low DC voltage to high AC voltage and an igniter to output high DC voltage. The total system block diagram of the HID lamp system is shown in Figure 1 [5]. 
The topologies applicable at the DC-DC converter are flyback, forward, or pushpull converters. The flyback converter can operate like buck-boost converter. In addition, it can easily output high DC voltage. Therefore, it is utilized as the DC-DC converter of the HID lamp system. The DC-AC inverter converts DC voltage to AC voltage and supplies AC voltage to the lamp. It has half-bridge or full-bridge inverter topology. The half-bridge inverter has an advantage of reducing the number of power semiconductor switches. However, the half-bridge inverter has a disadvantage that requires switches whose blocking voltage is high with possibility of voltage unbalance in DC-link capacitors. If a full-bridge topology is used in the DC-AC inverter, the switch number will be higher than that of the half-bridge. However, it has advantages that switch blocking voltage is half of the half-bridge type, and the voltage unbalance is not happen [6-8].

\section{The Proposed D1S Lamp System}

The total circuit of the proposed D1S lamp system is shown in Figure 2. The D1S lamp driver in the proposed system is roughly consisted of a DC-DC converter, a DC-AC inverter, and a voltage doubler that can generate high DC voltage for igniter operation.

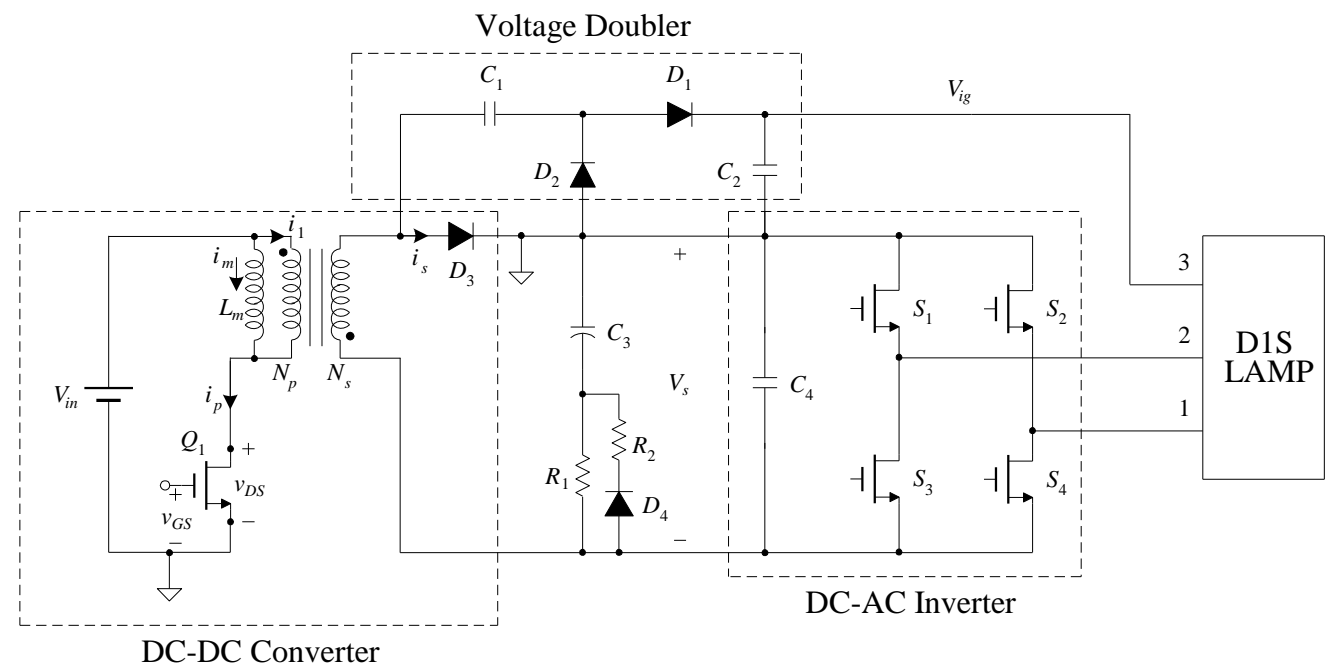

Figure 2. Total Circuit of the Proposed D1S Lamp System

\subsection{Operation Characteristics of the D1S Lamp}

The D1S lamp is an HID lamp developed recently. It has an internal circuit as shown in Figure 3. Because the D1S lamp is integrated with the arc-gap part, it has advantage of reducing the size of the lamp system. Due to this advantage, D1S lamp is widely used as car headlight lamp. The conceptual operation waveform according to the D1S lamp specification is shown in Figure 4 [9]. 


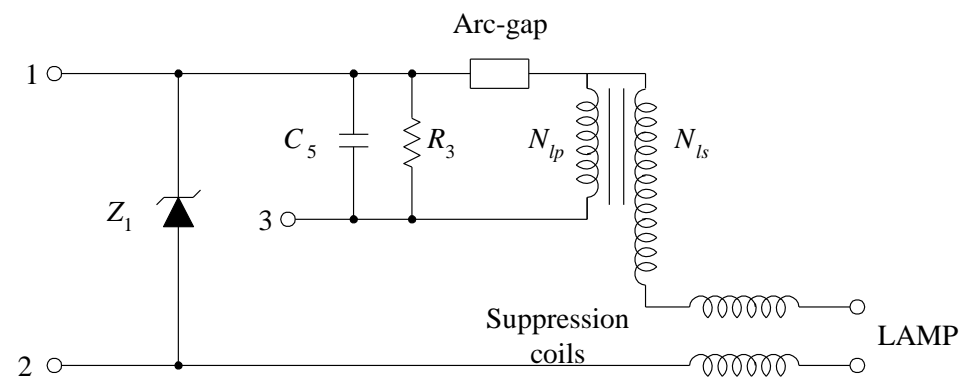

Figure 3. The Internal Circuit of the D1S Lamp

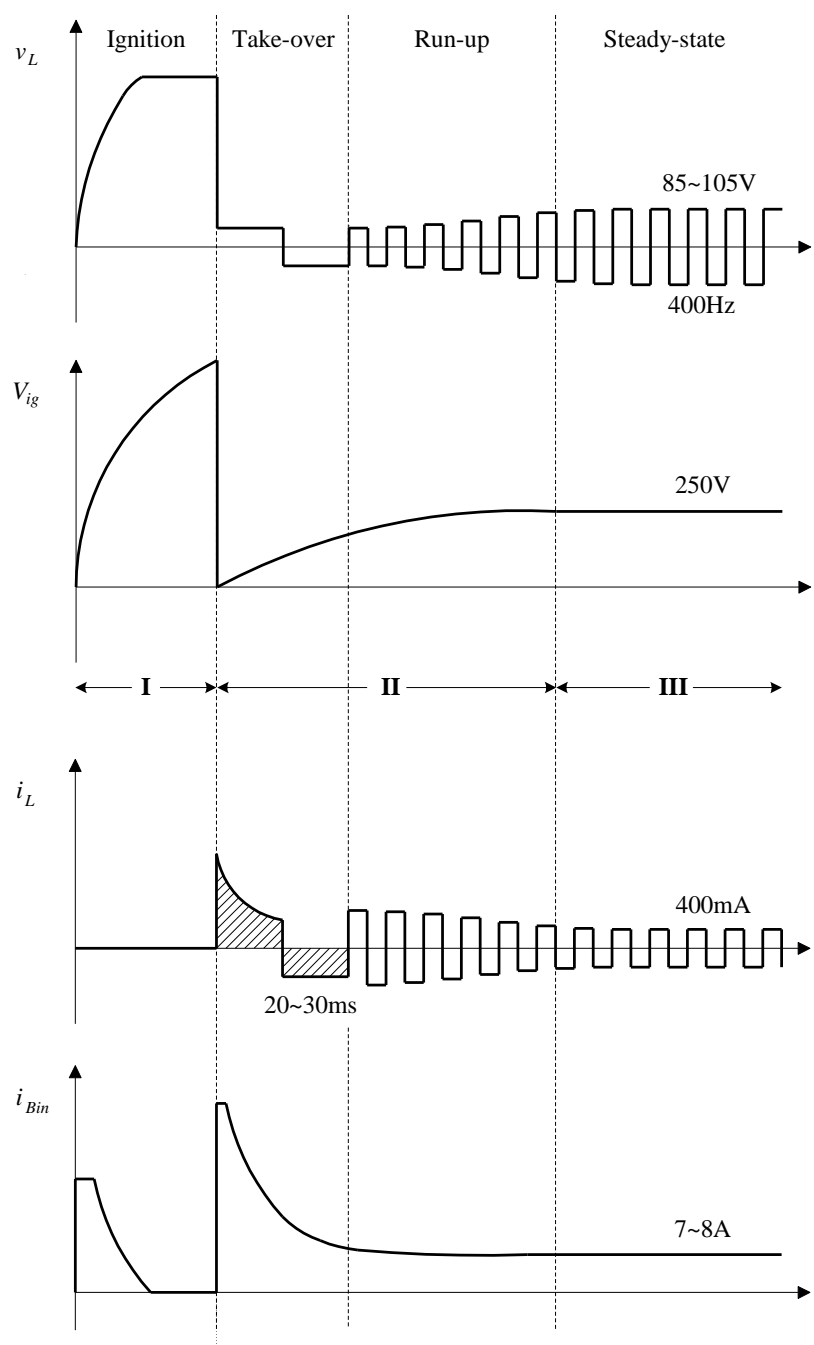

Figure 4. The Operation Conceptual Waveform According To the D1S Lamp Specification

The 'section I' in Figure 4 is the ignition section. It can raise the voltage to the ignition voltage so that the arc-gap can generate spark. Because the lamp does not turn on in this section, lamp resistance becomes very big. Therefore, the lamp operates like open-circuit in this section. After this, a spark is generated at the lamp so that the lamp can turn on. Now the lamp operation enters 'section II'. If the lamp turns on, the internal lamp temperature will rise, resulting in more active progress of lamp conduction. Now the lamp operation enters a steady state. At this time, if both 
electrodes are not heated enough, lamp conduction will not make active progress. In this case, the lamp will not turn on. Thus, the time for lamp operation to arrive at a steady state will become long. Therefore, enough current must be given to both lamp electrodes so that the lamp can enter steady state fast. The 'section III' is the steady state. At this state, lamp power must be kept constant through power control by the lamp driver.

\subsection{DC-DC Converter}

The flyback converter used as a DC-DC converter in the proposed driver does not need an output inductor. Therefore, it has an advantage of maintaining output voltages constant for various load or input sources. In addition, it is easy for multiple output applications. The DC-DC converter of the flyback converter topology used in the proposed driver operates with a constant off-time control method. All converter components are assumed ideal for analysis purpose except that the transformer is the ideal transformer with magnetizing inductance. The converter operates at critical conduction mode [10,11]. The theoretical operation waveform of the flyback converter is shown in Figure 5. The driving turn-on gatesource voltage $v_{G S}$ of the flyback converter switch $Q_{1}$ is generated after the off-time is maintained constant. When the switch peak current is arrived at the nominal reference value, the switch $Q_{1}$ is turned off. The design specifications of the prototype in this paper are: the input battery voltage $V_{i n}=9 \sim 15 \mathrm{~V}$, the rating output power $P_{o}=35 \mathrm{~W}$, and the efficiency $\eta=88 \%$. The transformer is designed with a primary magnetizing inductance $L_{m}=3 \mu \mathrm{H}$ and the turn ratio $n_{T}\left(=N_{s} / N_{p}\right)=6$ considering both lamp system size and voltage stress of power semiconductor switches.

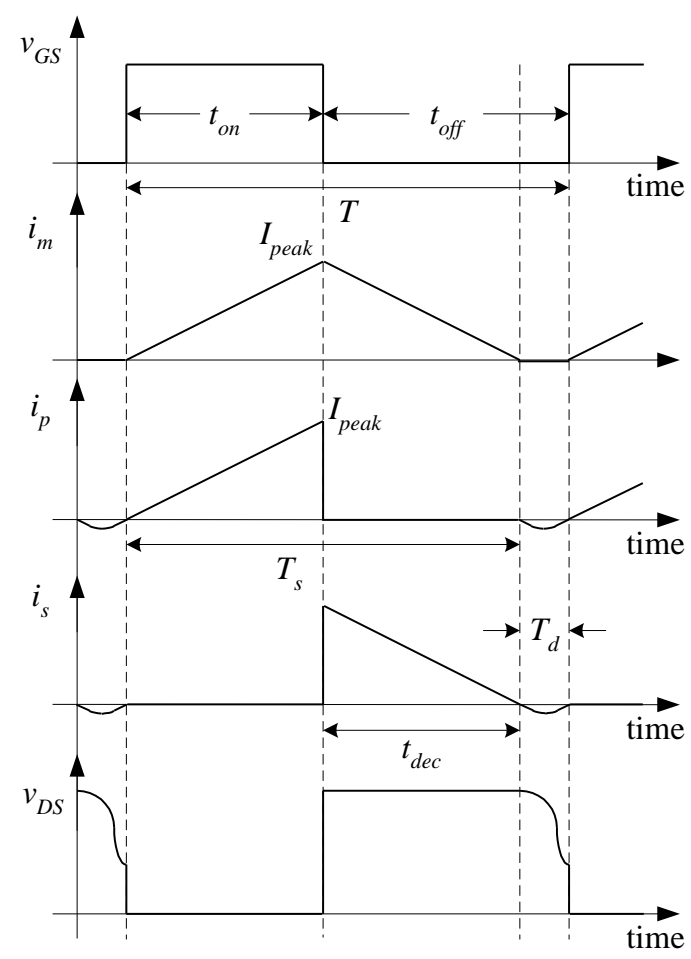

Figure 5. The Theoretical Operation Waveform of the DC-DC Converter 
The peak current $I_{p \text { eak }}$ of the transformer primary switch current $i_{p}$ is related to the switch on time $\left(t_{o n}\right)$ and the current decreasing time $\left(t_{d e c}\right)$ as follows:

$$
I_{\text {peak }}=\frac{V_{\text {in }} t_{\text {on }}}{L_{m}}=\frac{V_{s} t_{\text {dec }}}{n_{T} L_{m}}
$$

Here, for a switching period $T$, the average value $I_{s}$ of the transformer secondary current $i_{s}$ is calculated as:

$$
I_{S}=\frac{I_{\text {peak }}}{2 n_{T}} \frac{t_{d e c}}{T}
$$

From (1) and (2), the relationship between the switch on time $t_{o n}$ and the decreasing time $t_{d e c}$ is expressed as:

$$
\frac{t_{\text {on }}}{t_{\text {dec }}}=\frac{M}{n_{T}}
$$

where $M\left(=V_{\mathrm{s}} / V_{\text {in }}\right)$ is the voltage conversion ratio. From (1) and (2), the other average value $I_{s}$ of the transformer secondary current is calculated as:

$$
I_{s}=\frac{V_{S}}{2 L_{m} T}\left(\frac{t_{d e c}}{n_{T}}\right)^{2}
$$

If the converter operates with the critical conduction mode, the magnetizing current conduction time $T_{s}$ is as follows:

$$
T_{s}=t_{o n}+t_{d e c}
$$

The switching period $T$ is given by:

$$
T=T_{s}+T_{d}
$$

where $T_{d}$ is equal to half of the parasitic-resonance period as follows:

$$
T_{d}=\pi \sqrt{L_{m} C_{s}}
$$

where $C_{s}$ is equal to the sum of the parasitic capacitance of the power semiconductor switch $Q_{1}$ and the transformer primary-reflected parasitic capacitance of diode $D_{3}$. Because $T_{s} \gg T_{d}, T_{d}$ can be ignored. Therefore, $T$ can be approximated as $T_{\mathrm{s}}\left(T \approx T_{s}\right)$. Thus, $I_{s}$ of (4) can be rewritten as follows:

$$
I_{s}=\frac{V_{s}}{2 L_{m} T_{s}}\left(\frac{t_{d e c}}{n_{T}}\right)^{2}
$$

From (3), (5), and (8), current decreasing time $t_{d e c}$ and magnetizing current conduction time $T_{s}$ are obtained as:

$$
\begin{gathered}
t_{\text {dec }}=2 \frac{I_{s}}{V_{s}} L_{m} n_{T}^{2}\left(1+\frac{M}{n_{T}}\right) \\
T_{s}=2 \frac{I_{s}}{V_{s}} L_{m} n_{T}^{2}\left(1+\frac{M}{n_{T}}\right)^{2}
\end{gathered}
$$

If the lamp driver controls the output of the DC-DC converter with the critical conduction mode, its output power $P_{o}$ can be calculated as follows:

$$
P_{o}=\frac{T_{S}}{2 L_{m}}\left[\frac{V_{s}}{n_{T}\left(1+\frac{V_{S}}{n_{T} V_{\text {in }}}\right)}\right]^{2}
$$

Each analog voltage/current value necessary for the control of the proposed driver is sensed using an $\mathrm{A} / \mathrm{D}$ converter (analog to digital converter) of the microprocessor, the main controller of the proposed driver. The pulse-width modulation (PWM) pulse for driving of the converter switch $Q_{1}$ is generated by the flyback converter 
control and switch on/off routines of the microprocessor using the sensed values and (5).

\subsubsection{DC-AC Inverter}

The main role of full-bridge DC-AC inverter of the DC-AC converter part in Figure 2 is to convert DC voltage generated from the former DC-DC converter to square wave AC voltage of $400 \mathrm{~Hz}$ to supply it to the lamp. However, it does not operate duration lamp ignition in the initial operation of the system. Instead, it starts switching after lamp ignition. As shown in Figure 2, because the upper part voltage (the positive (+) voltage pole) of the DC link of the DC-AC inverter to the base voltage of the lower part is connected to the ground system, it has a negative (-) voltage. Therefore, the gate drive circuit of the power semiconductor switches $S_{1} \sim S_{4}$ is slightly complicated. This is the reason why there is a level shift problem of the gate drive voltage. In order to solve this problem, the proposed driver uses bootstrap method because this type circuit is less complicated compared to the other drive circuits. In addition, the IC's for this method have already been developed and commercialized. The drive circuit for the bridge of power semiconductor switches using bootstrap method is shown in Figure 6. The leg drive circuit of full bridges is realized by a bootstrap IC, where $V_{\text {drive }}$ is the generated drive voltage respect to the base voltage. Negative (-) voltage and switching signals for the switches are generated from the PWM module of the microprocessor used as the main controller.

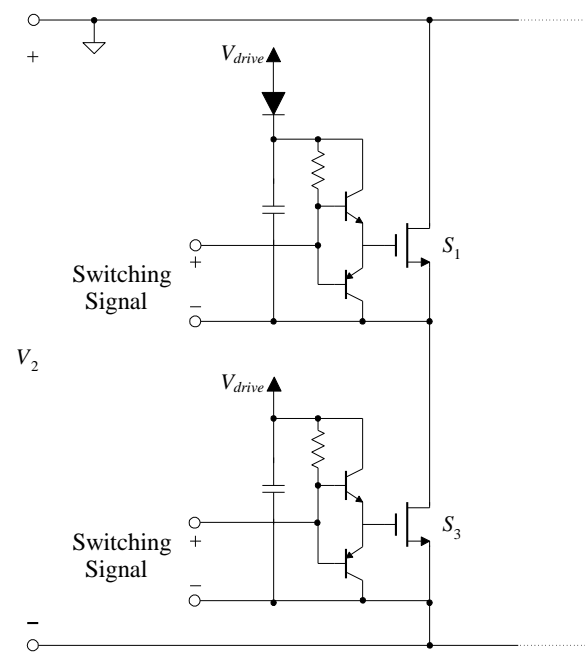

\section{Figure 6. A Drive Circuit for the Bridge of Power Semiconductor Switches using Bootstrap Method}

\subsubsection{Part Related to the Igniter}

The lamp used in the proposed system is a D1S lamp that is integrated with the arc-gap. The part related to the igniter for the lamp ignition is consisted of a voltage doubler generating high voltage and the arc-gap included in the D1S lamp. The circuit diagram of the voltage doubler and the arc-gap included in the D1S lamp is shown in Figure 7.

The ignition stage and the operation principles of the voltage doubler and the igniter are explained as follows:

1) The voltage doubler: At lamp ignition stage, the transformer secondary volt age of the DC-DC converter is induced, generating square wave voltage with amplitude 
$-n_{T} V_{i}(=-U)$. After this square wave voltage passes through the clamper of $C_{1}$ and $D_{2}$, it becomes square wave voltage with the amplitude $+U$. After this square waveform voltage again passes through $D_{1}$ and $C_{5}$, the upper voltage of $C_{5}$ becomes $+U$ while the lower voltage of $C_{5}$ becomes $-U$. Therefore, the arc-gap input voltage of the capacitor $C_{5}$ is doubled $(+2 U)$ from the secondary voltage of the DC-DC converter transformer with windings $N_{p}$ and $N_{s}$.

2) The igniter: At lamp ignition stage, if the voltage charged at $C_{5}$ passes over a threshold voltage of the arc-gap, it will generate a few $\mathrm{kV}$ arc. Such arc will raise the lamp voltage to a few $10 \mathrm{kV}$ using the windings $N_{l p}$ and $N_{l s}$, thus generating the starting voltage of the lamp. After the lamp ignition ends, because the voltage does not rise to the threshold voltage, the arc is not generated. The voltage of the capacitor $C_{5}$ will discharge through the resistor $R_{3}$ and keep under the threshold voltage of the arc-gap.

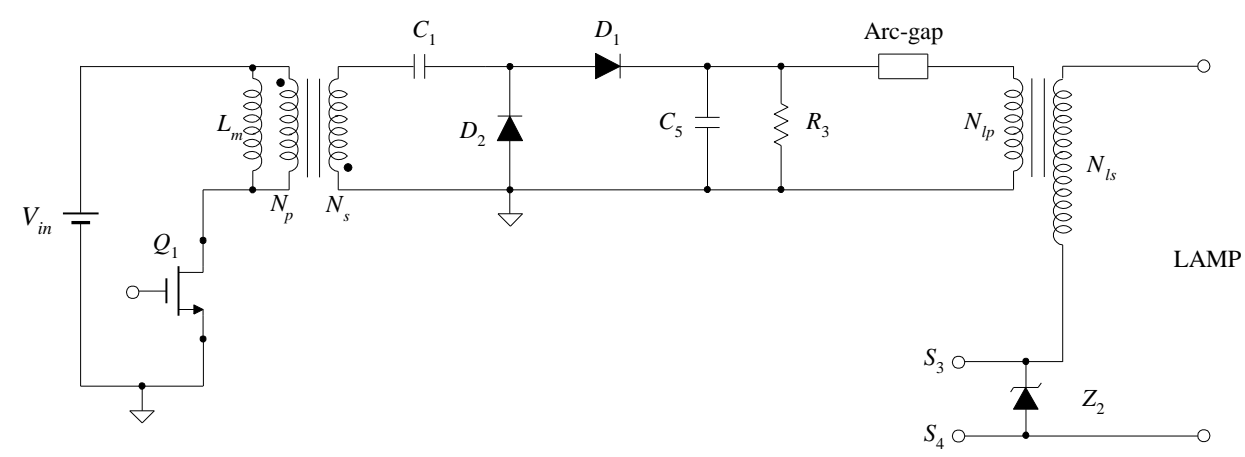

Figure 7. The Voltage Doubler and the Arc-Gap Included In the D1S Lamp 


\section{Experimental Results}

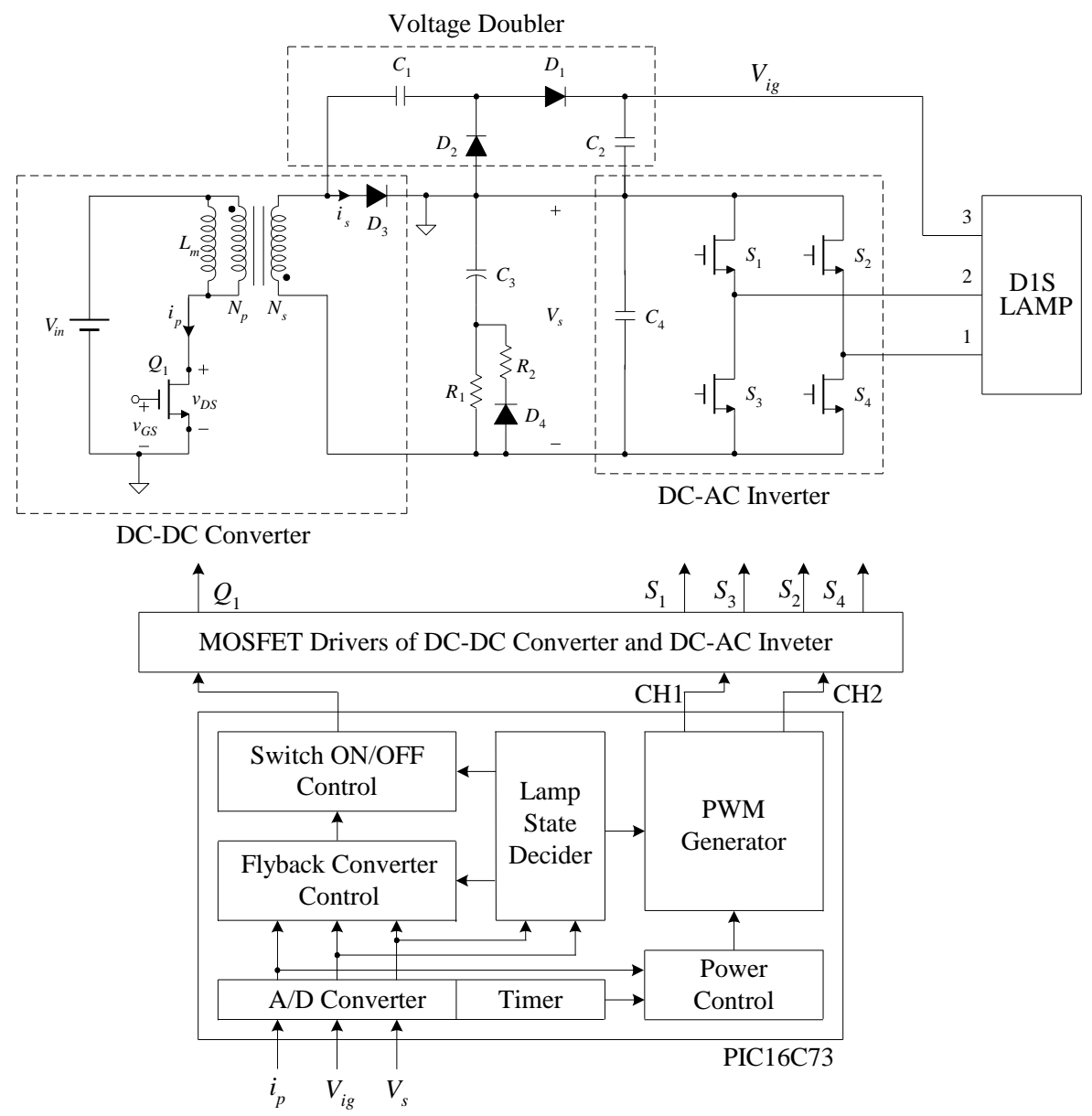

\section{Figure 8. The Total System Block Diagram of the Proposed D1S Lamp System}

Software flexibility in the system makes it easy to develop and update control technique by using microprocessors. The introduction of modern control technique with high performance is possible. In addition, control circuits can be simplified. The total system block diagram of the proposed D1S lamp system is shown in Figure 8. Due to these advantages of microprocessor, a low-cost 8-bit one-chip microprocessor of Microchip PIC16C73 is utilized as the main controller of the proposed system. The measured voltage/current values at each point are then inputted to $\mathrm{A} / \mathrm{D}$ converters and converted to digital values.

The overall system is divided into two parts: controller and power circuits. The controller part consists of the CPU circuit of the microprocessor PIC16C73 running the proposed control algorithms and driver circuits for driving Metal-Oxide Semiconductor Field Effect Transistors (MOSFETs). To reduce the size of the proposed system, the transformer size of the DC-DC converter is reduced and its main switch is switched at high frequency (operates at $f=110 \mathrm{kHz}$ ). After lamp ignition, the PWM frequency generated for the DC-AC inverter is $400 \mathrm{~Hz}$ according to the D1S lamp specification for AC-control of the lamp. 


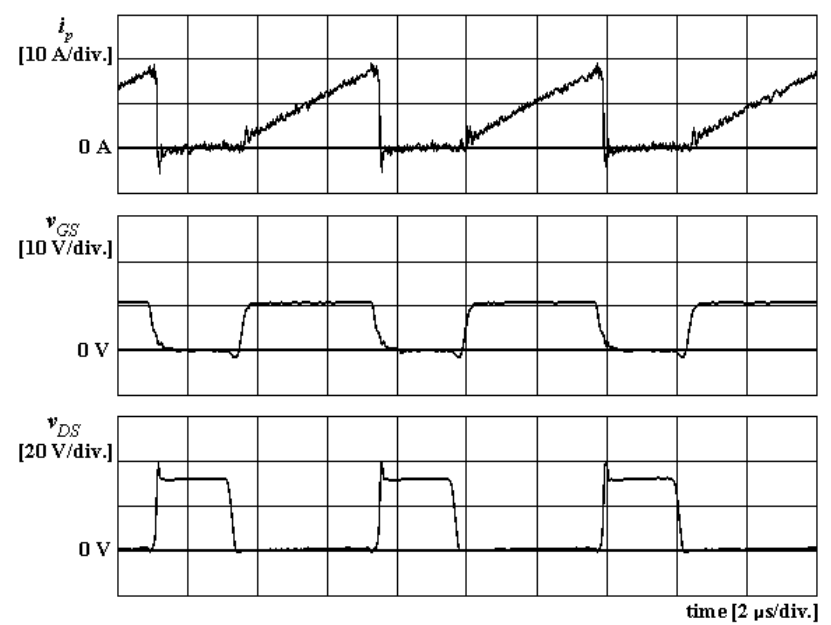

Figure 9. The Steady State Operation Waveform of DC-DC Converter

The steady state waveform of the DC-DC converter of the flyback converter topology operating with discontinuous conduction mode is shown in Figure 9. After the switch current $i_{p}$ passes over a discontinuous conduction period by constant turnoff time, if the switch turns on, the current will increase linearly. If the switch turns off, the current will not conduct. It will enter a discontinuous conduction mode. This waveform shows that the DC-DC converter of the proposed driver is operating well and stably.

An operation waveform of each part of the proposed system when the D1S lamp starts cold (initial ignition) is shown in Figure 10, where $v_{L}$ is the lamp voltage, $V_{i g}$ is the ignition voltage of the igniter, $i_{B i n}$ is the input battery current of the DC-DC converter, and $i_{L}$ is the lamp input current. This waveform shows that the operation waveform of the proposed driver for a cold lamp nearly coincides with the theoretical waveform, indicating that the proposed system meets manufacturer's required specifications.

An operation waveform of each part of the proposed system when the D1S lamp has a hot start (re-ignition after the lamp operates one more) is shown in Figure 11. Only the time of the take-over and run-up is a little bit longer than those of a cold start. However, the waveform shape is nearly similar to that of a cold start. In addition, the voltage is a little bit higher than that of a cold start while the current is a little bit lower than that of the cold start. This waveform also shows that the proposed system meets manufacturer's required specifications. 

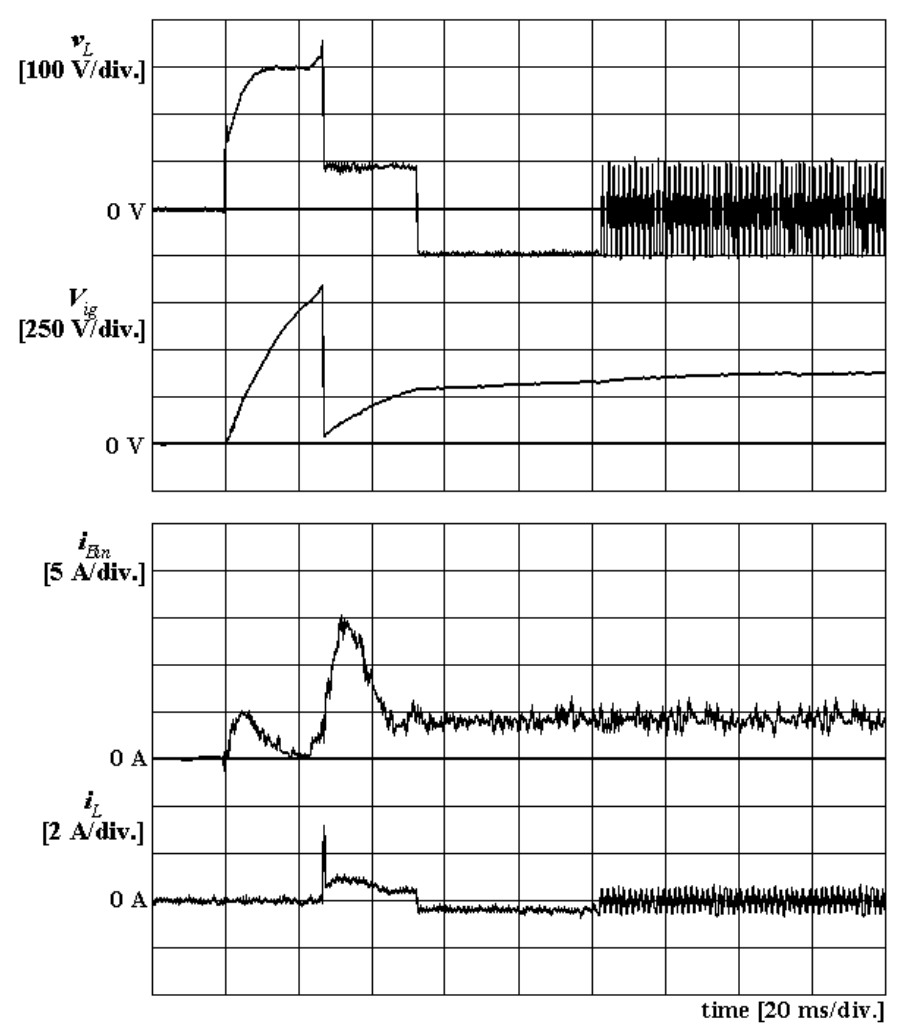

Figure 10. Operation Waveform of Each Part of the Proposed System When the D1S Lamp Has a Cold Start
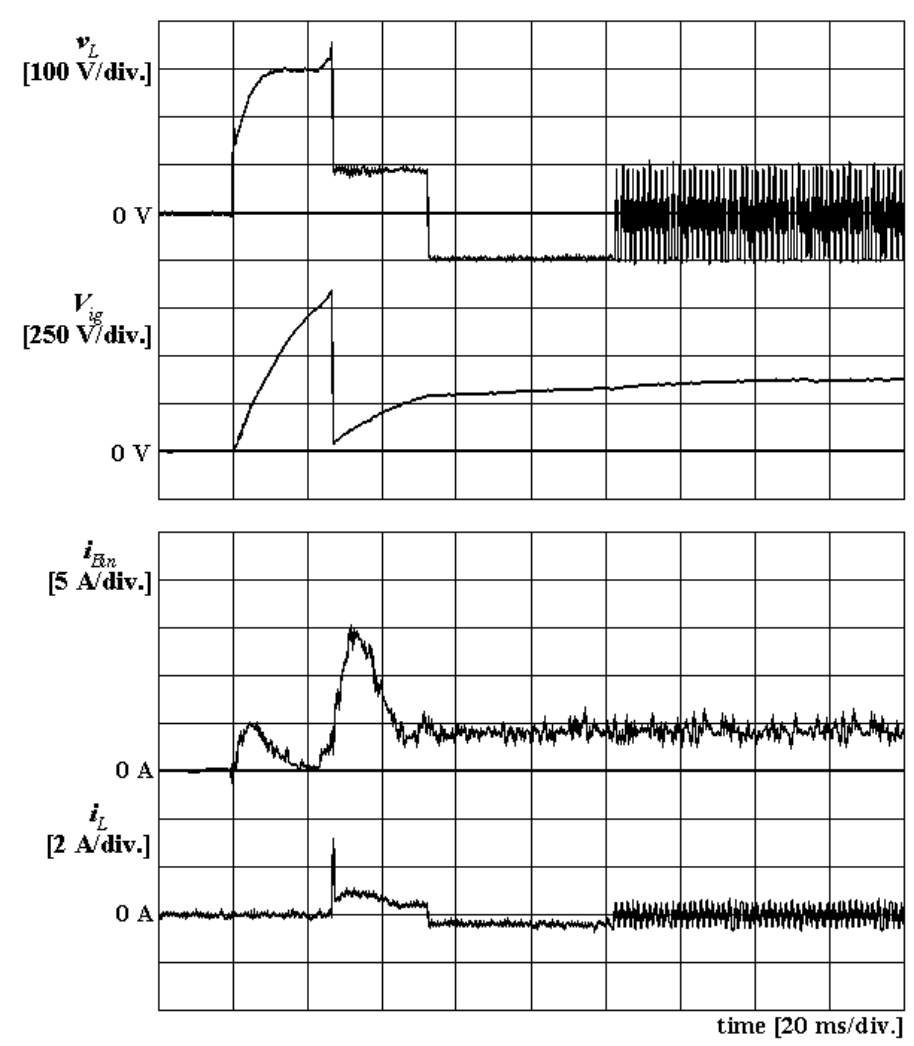

Figure 11. Operation Waveform of Each Part of the Proposed System When the D1S Lamp Has a Hot Start 
Lamp voltage and current at steady state are shown in Figure 12. The proposed driver can control the lamp current well with $\mathrm{AC}$ voltage at steady state.

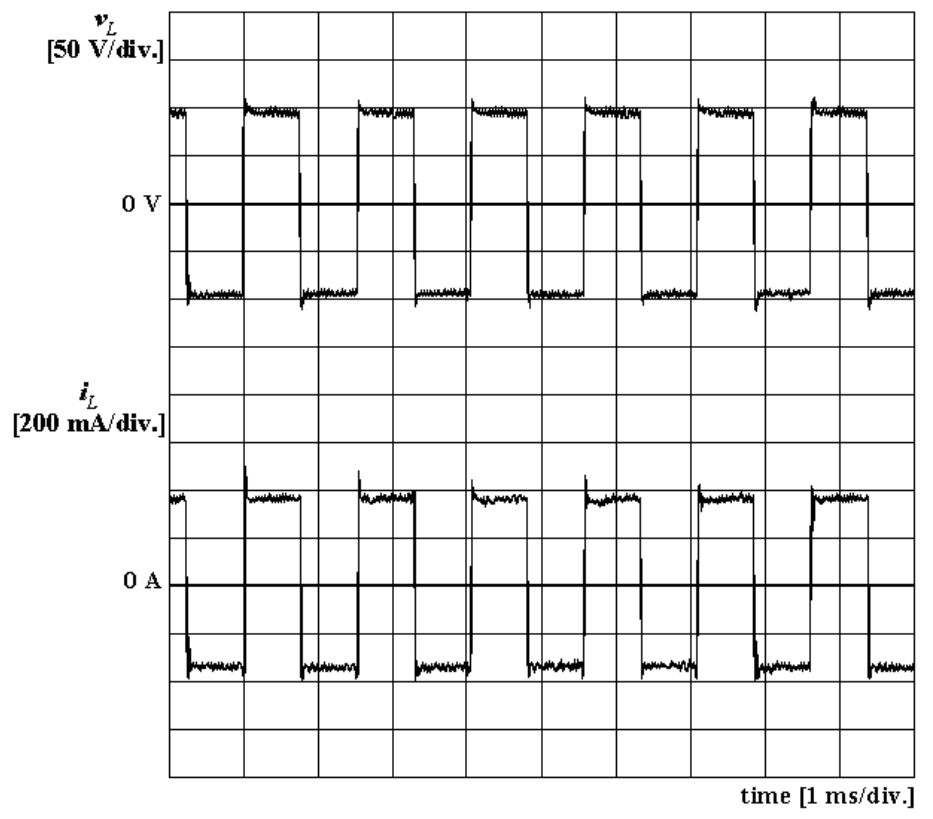

Figure 12. Lamp Voltage and Current at Steady State

\section{Conclusion}

In this paper, a simple digital D1S lamp system with power structure of a flyback converter and full-bridge inverter is presented. To optimize the size of the proposed system and minimize implementation cost through minimizing the total component number, all control functions are implemented using a low-cost 8-bit microprocessor. The proposed driver can generate high open-circuit voltage to ignite the lamp. It can be controlled to effectively supply lamp drive power after the ignition. The DC-DC converter in this proposed system utilizes the flyback converter to minimize component number. To further minimize the size of the total system, the transformer size is minimized by using microprocessor to generate high frequency PWM pulse. When the operation of the system arrives at a steady-state, the driver controls the lamp with AC current. In this paper, the operation principle of the proposed driver is described in details and the operation principle of the part related to the igniter is explained briefly. Experimental results demonstrate that the proposed driver has good performance for D1S lamp.

\section{Acknowledgments}

This work was supported by the Soonchunhyang University Research Fund. 


\section{References}

[1] H. Kakehasi, M. Habu, T. Ninomiya, M. Shoyama, H. Ogasawara and Y. Ohta, "Analysis of an HIDlamp igniter using a two-stage magnetic-pulse-compression circuit", Power Electronics Specialists Conference, 1998. PESC 98 Record. vol. 2, (1998), pp. 1768 - 1773.

[2] H. Ohguchi, M. H. Ohsato, T. Shimizu, G. Kimura and H. Takagi, "A high-frequency electronic ballast for HID lamps based on a $\lambda / 4$-long distributed constant line", IEEE Trans. on. Power Electron, vol. 13, no. 3, (1998), pp. 1023-1029.

[3] H. J. Faehnrich and E. Rasch, "Electronic ballasts for metal halide lamps", J. Illum. Eng. Soc., (1998), pp. 131-140.

[4] R. Fiorello, "Lamp igniter circuit", Tech. Rep., (1997)

[5] T. J. Liang, W. B. Shyu, C. A. Cheng, C. M. Chuang and J. F. Chen, "Investigation on transient and steady-state characteristics with electronic ballast of automotive HID lamp", PESC2002, (2002), pp. 1651-1655.

[6] M. G. Kim, G. Y. Park, D. H. Yoo and G. Y. Jeong, "Hihg Power Full-Bridge DC-DC Converter using a Center-Tapped Transformer and s Full-Wave Type Rectifier", IJCA, vol. 7, no. 4, (2014), pp. 267-278.

[7] S. H. Kwon, D. H. Yoo and G. Y. Jeong, "High-Efficiency AC-DC Switch-Mode Power Supply Using Full-Bridge Converter Circuits", IJCA, vol. 7, no. 6, (2014), pp. 189-200.

[8] G. Y. Jeong, "Analysis and Implementation of a Low-cost High Frequency Inverter for Driving a Nonlinear Load”, IJCA, vol. 8, no. 2, (2015), pp. 187-196.

[9] K. W. Hong, "Analysis and implementation of a high intensity discharge (HID) lamp ballast", POSTECH, M. S. Thesis, (2000).

[10] Y. Panov and M. M. Jovanovic, "Adaptive off-time control for variable-frequency, soft-switched flyback converter at light loads", IEEE Trans. on Power Electron., vol. 17, no. 4, (2002), pp596-603.

[11] K. C. Lee and B. H. Cho, "Design and analysis of automotive high intensity discharge lamp ballast using micro controller unit", IEEE Trans. on Power Electron. vol. 18, no. 6, (2003), pp. 1356-1364.

\section{Author}

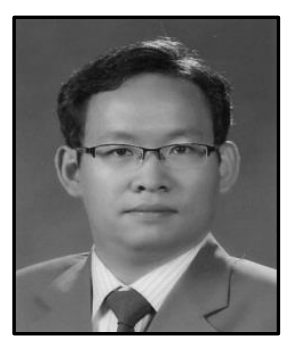

Gang-Youl Jeong, he received his M.S. and Ph.D. degrees in Electronic and Electrical Engineering from POSTECH (Pohang University of Science and Technology), Korea, in 1999 and 2002, respectively. He has been a professor in the Department of Electronic Information Engineering, Soonchunhyang University, Korea. His research interests include DC-DC power converters, AC-DC high-frequency inverters, and power conversion for renewable energy. 
International Journal of Control and Automation

Vol. 9, No. 12 (2016) 